\title{
A Fractional Creep Constitutive Model for Frozen Soil in Consideration of the Strengthening and Weakening Effects
}

\author{
Feng Hou, ${ }^{1}$ Quanming Li, ${ }^{2}$ Enlong Liu, ${ }^{1,3}$ Cheng Zhou, ${ }^{1}$ Mengke Liao, ${ }^{3}$ \\ Huiwu Luo, ${ }^{1}$ and Xingyan Liu $^{3}$ \\ ${ }^{1}$ State Key Laboratory of Hydraulics and Mountain River Engineering, College of Water Resources and Hydropower, \\ Sichuan University, Chengdu 610065, China \\ ${ }^{2}$ China Academy of Safety Science and Technology, Beijing 10012, China \\ ${ }^{3}$ State Key Laboratory of Frozen Soil Engineering, Cold and Arid Regions Environmental and Engineering Institute, \\ Chinese Academy of Sciences, Lanzhou 730000, China
}

Correspondence should be addressed to Enlong Liu; liuenlong@lzb.ac.cn

Received 3 February 2016; Accepted 20 April 2016

Academic Editor: Jarir Aktaa

Copyright (C) 2016 Feng Hou et al. This is an open access article distributed under the Creative Commons Attribution License, which permits unrestricted use, distribution, and reproduction in any medium, provided the original work is properly cited.

The triaxial creep tests of frozen silty clay mixed with sands were performed under different pressures, and the test results demonstrated that, under the low confining pressure, when the shear stress is lower than the long-term strength, the test specimen exhibits an attenuation creep because the strengthening effect is greater than the weakening effect. When the shear stress is higher than the long-term strength, the test specimen exhibits a nonattenuation creep due to the level of the strengthening and weakening effects change in different stages. As the confining pressure increases, the test specimens only exhibit an attenuation creep because of the enhancing strengthening effect. Both the hardening parameter and the damage variable were introduced to describe the strengthening and weakening effects, respectively, and a new creep constitutive model for frozen soil considering these effects was put forward based on the theory of elastoviscoplastic and the fractional derivative. Finally, the model parameters were analyzed and their determination method was also provided to reveal the trend of parameters according to the triaxial test results. The calculated results of the constitutive model show that the proposed model can describe the whole creep process of frozen soil well.

\section{Introduction}

Frozen soil is a kind of special geological material. In the past decades, with the increase of the projects constructed in frozen soil regions in the Qinghai-Tibet Plateau [1], many engineering problems are arising. One of the big problems for these projects built on frozen ground is the settlement due to temperature change and external loads [2]. For the sources of the settlement, many investigators focused on the thaw settlement of permafrost [3-5], while the creep of frozen soils was neglected. The creep, however, may play a big role in the total settlement due to the complexity of the frozen soil. And thus, as a common source of the settlement in cold regions, the creep of frozen soils should always be seriously taken into consideration $[6,7]$.
The elementary rheological modeling is a method to study creep property of frozen soil, by which the physical relationship can be characterized by a series of mechanical elements, for example, Hookean spring, Newtonian dashpot, and Saint Vernant's slider. Li et al. [8] deduced an improved Nishihara creep model for the frozen deep clay by combining a generalized Kelvin model and an improved viscoplastic body. Wang et al. [9] proposed a simple model by combining Maxwell, Kelvin, and Bingham body with a parabolic yield criterion so as to describe the settlement of underlying warm and ice-rich permafrost. In recent years, many studies have been performed in the theory of fractional derivative which provides a new train of thought for the creep. Enelund et al. [10] proposed that the fractional calculus could describe the mechanical behavior of viscoplastic solid materials. Zhou 


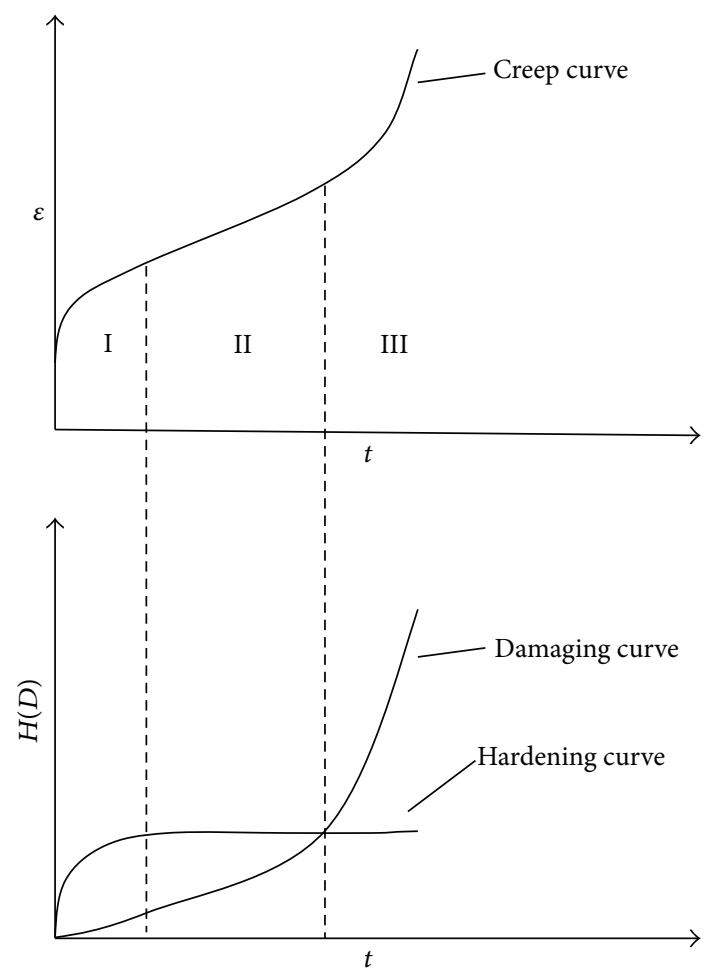

Figure 1: Sketch of creep, damage, and hardening curves.

et al. [11, 12] proposed a fractional order creep constitutive model to research the creep of salt rock by replacing a Newtonian dashpot into Nishihara's model with a fractional derivative Abel dashpot. Kang et al. [13] proposed a fractional nonlinear model to describe the creep behavior of coal by taking into account the elastoviscoplastic characteristics and the damage effect.

At present, with the development of the CT scanning technology [14-16], the rheological model based on mechanism analysis has been substantially developed, which focuses on the rheological deformation mechanism of the material, such as the fine microscale particles between the mobile and the evolution of the crack caused by the strengthening and weakening effect. Miao et al. [17] established the evolution equation and the general damage theory of frozen soil creep on the basis of the study on the creep test and its microstructure observation to depict the strengthening and weakening effects in the process of creep. However, many investigators just considered the weakening effect but lost sight of the strengthening effect when they formulated the creep models, but it is necessary to consider both the strengthening effect [18-20] and the weakening effect in the creep process according to the electron microscope scanning results of hardening and damage of sketch by Fan et al. [21] as shown in Figure 1. Therefore, in this paper, firstly, through the triaxial creep tests of the frozen silty clay mixed with sands, the strengthening and weakening effects in the process of creep are revealed. Then, based on the triaxial creep test results, the hardening parameter and damage variable are introduced to describe the strengthening and weakening

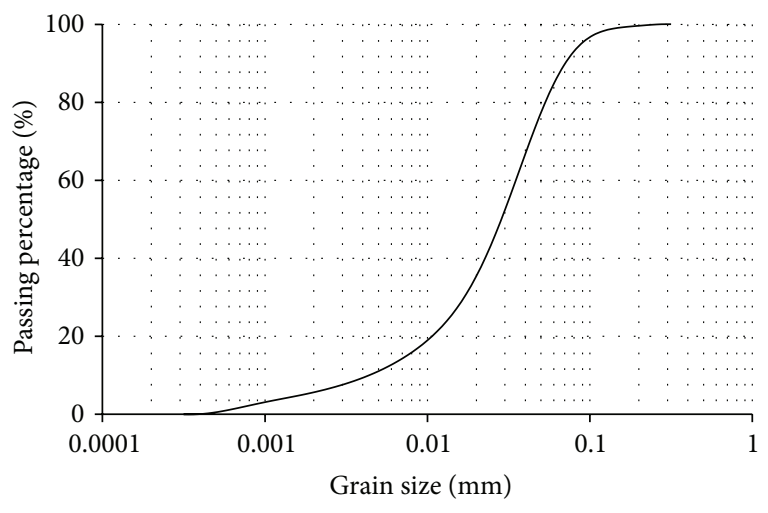

FIGURE 2: Grain distribution of the silty clay.

effects, respectively. Furthermore, a new fractional creep constitutive model considering the strengthening and weakening effects is put forward based on the theory of fractional derivative and elastic-plastic theory and verified with creep test results of frozen soils.

\section{The Triaxial Creep Test of the Frozen Silty Clay Mixed with Sand}

2.1. Test Conditions. The tested soils were silty clay and the quartz sand. Their physical parameters are shown in Table 1 and Figure 2, respectively. First, the silty clay, dried and sieved through the $1 \mathrm{~mm}$ screen, was prepared with water content of $16.0 \%$ and kept for $24 \mathrm{~h}$ without evaporation, so that its moisture was uniformly distributed. The silty clay and quartz sand were weighted according to the mass of soil and sand ratio of $100: 60$; then the prepared silty clay and quartz sand were mixed uniformity, filled in a cylindrical mold to make cylindrical soil specimens under certain compression rate provided by the sample-making machine, by which the specimens were prepared as cylinders with diameter and height of $6.18 \mathrm{~cm}$ and $12.5 \mathrm{~cm}$, respectively. Then, the specimens were placed in another mold with three same parts and saturated for over $12 \mathrm{~h}$ under a vacuum for $3 \mathrm{~h}$. In order to avoid large frost heaving and prevent moisture transmission, the soil specimens were placed in a refrigeration unit and frozen quickly and submerged in distilled water at a temperature of $-30^{\circ} \mathrm{C}$. After $48 \mathrm{~h}$ of freezing, the molds were removed and the specimens were mounted with epoxy resin plates on both ends and covered with a rubber sleeve to avoid moisture evaporation. Finally, the specimens were then kept in an incubator for over $24 \mathrm{~h}$ at the test target temperature of $-10^{\circ} \mathrm{C}$ such that the specimen adopted a uniform temperature.

The test equipment used in this study is a cryogenic triaxial apparatus modified from the MTS-810 material test machine, which contains the pressure chamber to apply the confining pressure and axial pressure, whose schematics were illustrated by Lai et al. [22]. After the specimens mentioned above were prepared, they were placed into the pressure cell of the MTS-810 material test machine and a series of the creep tests were performed. First, the temperature in the pressure chamber was set at $-10^{\circ} \mathrm{C}$ with a precision of $\pm 0.1^{\circ} \mathrm{C}$. Before 
TABLE 1: The physical parameters of the silty clay and quartz sand.

\begin{tabular}{lcccc}
\hline & Specific gravity & Liquid limit/\% & Plastic limit/\% & Water content $/ \%$ \\
\hline Silty clay & 2.72 & 27.58 & 19.37 & 1.35 \\
Quartz sand & 2.66 & - & - & 0.0 \\
\hline
\end{tabular}

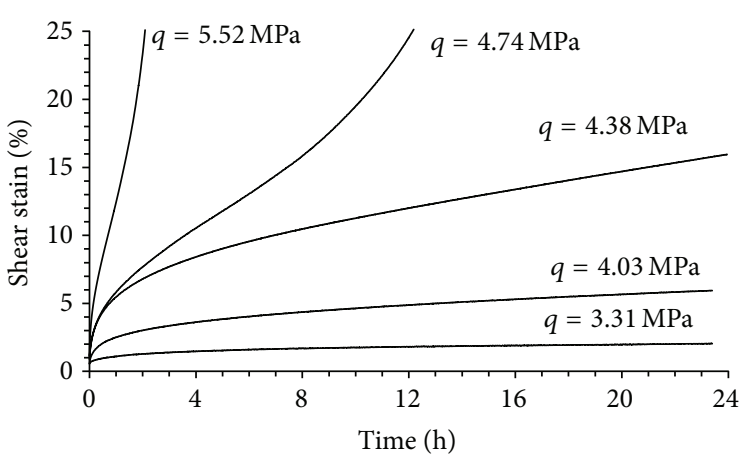

(a) $\sigma_{3}=0.3 \mathrm{MPa}$

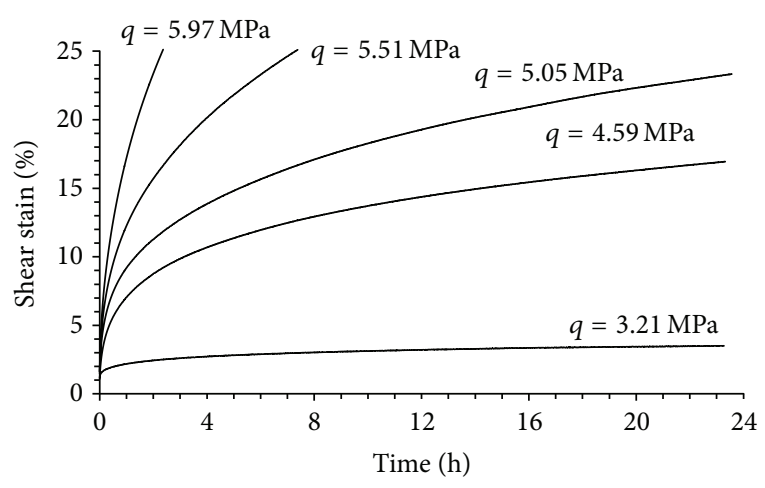

(b) $\sigma_{3}=1.4 \mathrm{MPa}$

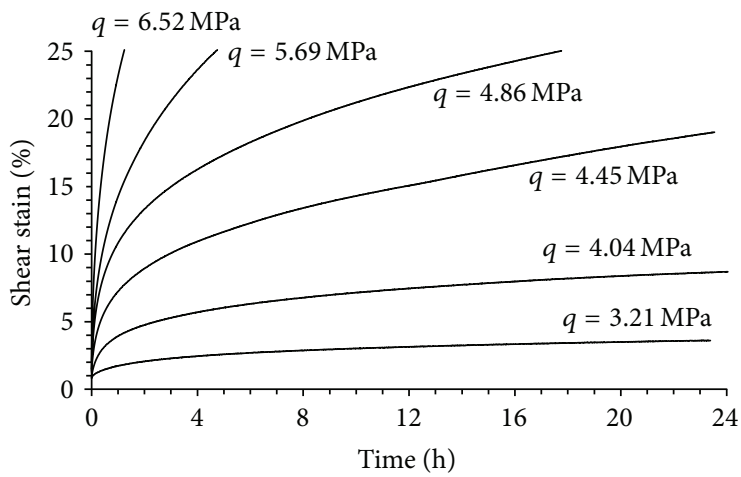

(c) $\sigma_{3}=6.0 \mathrm{MPa}$

FIGURE 3: Creep curves under different confining pressures.

the creep testing, the prepared specimen was consolidated under a preset pressure (0.3 MPa, $1.4 \mathrm{MPa}$, or $6.0 \mathrm{MPa})$ for $30 \mathrm{~min}$ prior to the axial load, respectively. Under each confining pressure, the triaxial creep tests on specimens were conducted under different stress levels. In the initial loading, the axial load was applied to the test specimen from 0 to the stress level value of the creep test within $60 \mathrm{~s}$. During the process of testing, the axial pressure on the specimens was kept constant with a precision of $\pm 10 \mathrm{kPa}$.

2.2. Test Results and Analyses. The curves of the axial straintime obtained by the creep tests under different confining pressures are shown in Figure 3. As can be seen from Figure $3(\mathrm{a})$, under the low confining pressure $(0.3 \mathrm{MPa})$, there are two types of creep, that is, an attenuate creep and a nonattenuate creep. When the shear stress is lower than the long-term strength, the deformation with time is an attenuate creep where the creep rate decreases over time. When the shear stress is higher than the long-term strength, it turns to be a nonattenuation creep and can be divided into three stages, that is, the unsteady stage, steady stage, and accelerating stage. The test specimen quickly fails once it enters the accelerating stage. However, from Figures 3(b) and $3(\mathrm{c})$, under the high confining pressures (e.g., 1.4 MPa and 6.0 MPa), we can know that there is only an attenuation creep.

Under the low confining pressure $\left(\sigma_{3}=0.3 \mathrm{MPa}\right)$ and a high shear stress level $\left(q=\sigma_{1}-\sigma_{3}=4.74 \mathrm{MPa}\right)$, the test specimen has experienced three creep stages. After a short initial strain the test specimen enters the unsteady stage where the pores contracts rapidly and then tends to enter the steady stage with a constant creep rate. At this stage, the mineral particles are arranged in disorder and the strengthening effect is predominant. When the test specimen has entered the steady stage, the microcracks start to grow in the places with the original defects and where the resulted stress is concentrated, and thus some of the soil particles are redirected along the shear plane and the damage increases dramatically. During this stage, the strengthening and weakening effects are in dynamic equilibrium, and the creep rate is unchanged. The 


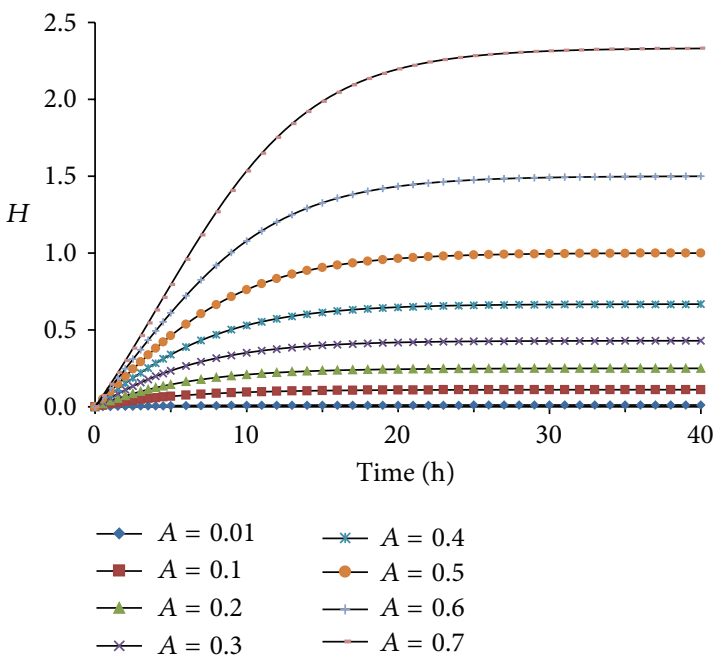

(a) The influence of parameter $A$

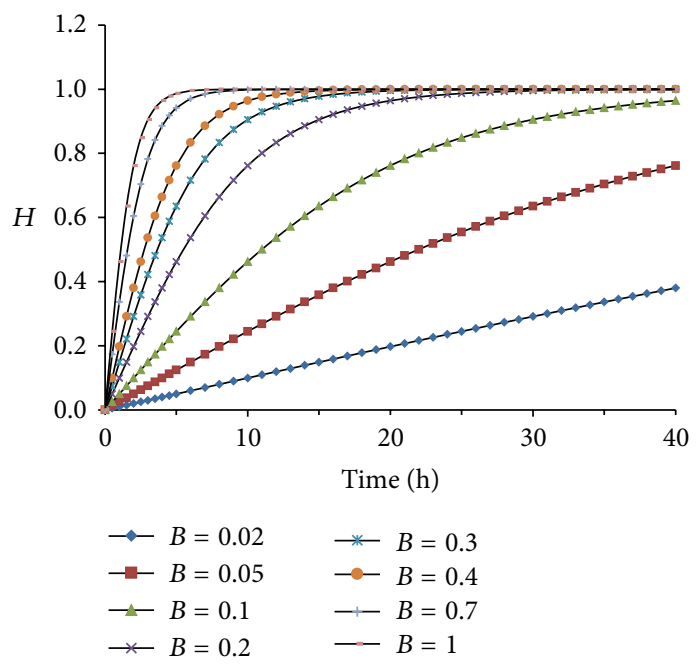

(b) The influence of parameter $B$

Figure 4: The influence of parameters $A$ and $B$ on hardening variable.

test specimen will enter the accelerating stage at the end of the steady stage, and the mineral grains move along the shear plane fiercely and the cracks continue to grow, with the weakening effect dominating at this state. The creep rate increases and the creep curve goes upward, eventually leading to destruction with the collapse of soil mass of skeleton and loss of bearing capacity.

Under the high confining pressures (e.g., $\sigma_{3}=1.4 \mathrm{MPa}$ and $\sigma_{3}=6.0 \mathrm{MPa}$ ), the internal space of test specimen is compressed and closed with the increase of the confining pressure, accompanied by the soil particles moving along the shear pane difficultly because of the large particle size of sand. At this stage, the weakening effect almost does not make any effects and the strengthening effect is predominant. Finally, there is only an unsteady creep stage in the creep process. Therefore, it is necessary to consider the strengthening and weakening effects in the process of creep.

\section{A Fractional Creep Constitutive Model for Frozen Soil in Consideration of the Strengthening and Weakening Effects}

\subsection{The Strengthening and Weakening Effects}

3.1.1. Hardening Parameter $H$. The soil pore will close with the increasing axial compression. Combining Figures 1 and 3 , hardening parameter $H$ can be introduced to describe the strengthening effect of the viscous coefficient in the creep process, which should have the following properties: $H \rightarrow 0$ when $t \rightarrow 0$ because of no creep compression at $t=0$ and $H \rightarrow a$ certain constant when $t \rightarrow \infty$. If only the stress and time are considered, we can define

$$
\eta_{\alpha}=\eta_{\alpha}(1+H)=\eta_{\alpha}(1+H(\sigma, t)),
$$

where $\eta_{\alpha}$ is the viscous coefficient; $H$ is the hardening parameter, and when $H=0$ it means that there is no strengthening effect; $\sigma$ is the stress; $t$ is the creep time. The hardening parameter in the creep process is assumed as

$$
H(\sigma, t)=\frac{1}{(1-A)+A e^{-B t}}-1
$$

where $A /(1-A)$ denotes the level of the strengthening effect, and the bigger its value is, the greater the strengthening effect is, with $0 \leq A<1 ; B$ is to denote the speed of strengthening effect in the process of creep, and the greater its value is, the faster the strengthening effect is, with $B>0$. Setting $B=0.2$ in (2), a bunch of curves of hardening parameters with different value of $A$ can be obtained; setting $A=0.5$ in (2), a bunch of curves of hardening parameters with different value of $B$ can be obtained (shown in Figure 4).

3.1.2. Damage Variable D. The experimental investigation has verified that the damage effect has an initiation condition [23]. Only if the loading stress exceeds such a certain stress, the microscopic cracks initiate, propagate, and evolve such that the creep damage accumulates and the accelerating creep occurs. The stain rate of the frozen soil increases nonlinearly in this process, and the failure will take place once the strain reaches a critical value [24]. Therefore, based on damage mechanics, we can define the damage variable as

$$
\begin{aligned}
& D(\sigma, t)=1-\frac{E(\sigma, t)}{E_{0}}, \\
& E(\sigma, t)=E_{0} \exp \left[-\chi \frac{\left\langle\sigma-\sigma_{\infty}\right\rangle}{\sigma_{\infty}} t\right],
\end{aligned}
$$

where $E(\sigma, t)$ is the elastic modulus at time $t ; E_{0}$ is the initial elastic modulus; $\sigma_{\infty}$ is the long-term strength; $\chi$ is 
the material constant; and $\left\langle\sigma-\sigma_{\infty}\right\rangle$ is a switching function defined as follows:

$$
\left\langle\sigma-\sigma_{\infty}\right\rangle= \begin{cases}0 & \sigma-\sigma_{\infty}<0 \\ \sigma-\sigma_{\infty} & \sigma-\sigma_{\infty} \geq 0\end{cases}
$$

Substituting (4) and (5) into (3), we have

$$
D(\sigma, t)= \begin{cases}0 & \sigma-\sigma_{\infty} \leq 0 \\ 1-e^{-C t} & \sigma-\sigma_{\infty}>0\end{cases}
$$

where $C=\chi\left(\sigma-\sigma_{\infty}\right) / \sigma_{\infty}$.

3.2. Theory of Fractional Derivative. There are a number of definitions of fractional calculus [12], and Riemann-Liouville definition is the most commonly used, which has the following definition: assuming that $f(t)$ is continuous in $(0,+\infty)$ and integrable in any finite sub of $[0,+\infty)$ and for $t>0$ and $\operatorname{Re}(\alpha)>0, \alpha$ order integral of the function $f(t)$ is expressed as

$$
\frac{d^{-\alpha} f(t)}{d t^{-\alpha}}={ }_{t_{0}} D_{t}^{-\alpha} f(t)=\frac{1}{\Gamma(\alpha)} \int_{t_{0}}^{t}(t-\tau)^{\alpha-1} f(\tau) d \tau,
$$

where $\Gamma(\cdot)$ is the Gamma function as follows:

$$
\Gamma(\alpha)=\int_{0}^{\infty} e^{-t} t^{z-1} d t, \quad \operatorname{Re}(\alpha)>0
$$

$\alpha$ order differential of the function $f(t)$ is expressed as

$$
\frac{d^{\alpha} f(t)}{d t^{\alpha}}={ }_{t_{0}} D_{t}^{\alpha} f(t)=\frac{d^{n}\left[{ }_{t_{0}} D_{t}^{-(n-\alpha)} f(t)\right]}{d t^{n}},
$$

where $\alpha>0$ and $n-1<\alpha \leq n$ ( $n$ is positive integer).

Combining the fractional calculus previously mentioned, the constitutive equation of Abel dashpot can be revised as follows [12]:

$$
\sigma(t)=\eta_{\alpha} \frac{d^{\alpha} \varepsilon(t)}{d t^{\alpha}}
$$

where $\eta_{\alpha}$ is the viscosity coefficient, having the expression in (1). When $\alpha=1$, it represents an ideal fluid known as the Newton dashpot, and when $\alpha=0$ it represents the ideal solid. Abel dashpot is used to simulate the material between ideal fluid and ideal solid.

When the stress $\sigma(t)$ is constant, applying the fractional integral to (10) according to (7), we can get

$$
\varepsilon(t)=\frac{\sigma}{\eta_{\alpha}} \frac{t^{\alpha}}{\Gamma(1+\alpha)} .
$$

3.3. A Fractional Creep Constitutive Model for Frozen Soil. Based on the above analysis, a fractional creep constitutive model for frozen soil considering the strengthening and weakening effects is proposed in this study, as shown in Figure 5.

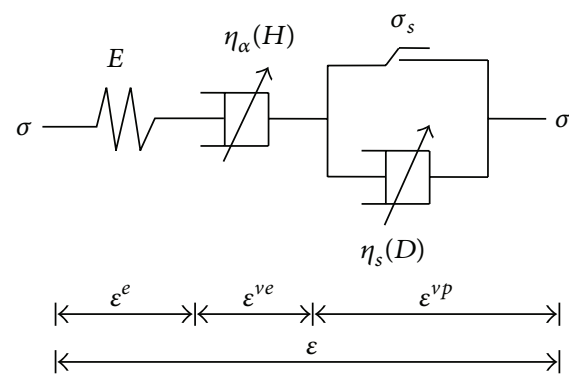

FIgURE 5: The representation of fractional creep constitutive model of frozen soil in consideration of the strengthening effect and weakening effect.

According to a series of rules, the following relation holds:

$$
\begin{gathered}
\varepsilon=\varepsilon^{e}+\varepsilon^{v e}+\varepsilon^{v p}, \\
\sigma=\sigma_{E}=\sigma_{\alpha}=\sigma_{v p},
\end{gathered}
$$

where $\sigma_{s}$ is the yield stress, which can be determined by the triaxial test; $\sigma_{E}$ and $\varepsilon^{e}$ are the stress and strain of the elastic element, with $\sigma_{E}=E \varepsilon^{e} ; \sigma_{\alpha}$ and $\varepsilon^{v e}$ are the stress and strain of Abel dashpot; $\sigma_{v p}$ and $\varepsilon^{v p}$ are the stress and strain of viscoplastic element; $\sigma$ and $\varepsilon$ are the total stress and strain.

(1) If $\sigma<\sigma_{s}$, according to the elastoplastic theory, $\varepsilon^{v p}=0$, then we have

$$
\varepsilon=\varepsilon^{e}+\varepsilon^{v e}
$$

The stress-strain relationship of the elastic element is

$$
\varepsilon^{e}=\frac{\sigma_{E}}{E}
$$

Substituting (1) and (2) into (10), the constitutive equation of Abel dashpot considering the strengthening effect is expressed as

$$
\sigma(t)=\frac{\eta_{\alpha}}{(1-A)+A e^{-B t}} \frac{d^{\alpha} \varepsilon^{v e}(t)}{d t^{\alpha}} \quad(0 \leq \alpha \leq 1),
$$

where $\sigma(t)$ is constant during the process of a creep test. According to the theory of fractional integral, we get

$$
\begin{aligned}
\varepsilon^{v e} & =\varepsilon^{v e}(t) \\
& =\frac{\sigma}{\eta_{\alpha} \Gamma(\alpha)} \int_{0}^{t}(t-\tau)^{\alpha-1}\left[(1-A)+A e^{-B \tau}\right] d \tau .
\end{aligned}
$$

So the relationship between the total stain and time can be obtained as follows:

$$
\begin{aligned}
\varepsilon & =\varepsilon^{e}+\varepsilon^{v e} \\
& =\frac{\sigma}{E}+\frac{\sigma}{\eta_{\alpha} \Gamma(\alpha)} \int_{0}^{t}(t-\tau)^{\alpha-1}\left[(1-A)+A e^{-B \tau}\right] d \tau .
\end{aligned}
$$

By the Taylor expansion of $e^{-B t}=\sum_{n=0}^{\infty}\left((-B t)^{n} / n !\right)$, we can obtain

$$
\begin{aligned}
\varepsilon & =\varepsilon^{e}+\varepsilon^{v e} \\
& =\frac{\sigma}{E}+\frac{\sigma t^{\alpha}}{\eta_{\alpha}}\left[\frac{1}{\Gamma(\alpha+1)}+A \sum_{n=1}^{\infty} \frac{(-B t)^{n}}{\Gamma(\alpha+1+n)}\right] .
\end{aligned}
$$


(2) If $\sigma \geq \sigma_{s}$, the initial stain, the viscoelastic stain, and the plastic stain contribute to the total strain, and the constitutive equation of the viscoplastic element considering the weakening effect can be written as

$$
\eta_{s}(1-D) \frac{d^{\beta} \varepsilon^{v p}(t)}{d t^{\beta}}+\sigma_{s}=\sigma .
$$

(i) If $\sigma_{s} \leq \sigma<\sigma_{\infty}, D=0$, (19) can be written as

$$
\eta_{s} \frac{d^{\beta} \varepsilon^{v p}(t)}{d t^{\beta}}+\sigma_{s}=\sigma .
$$

According to the definition of the fractional derivative, we can get

$$
\varepsilon^{v p}(t)=\frac{\sigma-\sigma_{s}}{\eta_{s}} \frac{t^{\beta}}{\Gamma(1+\beta)} .
$$

(ii) If $\sigma \geq \sigma_{\infty}, D=1-e^{-C t}$, (19) can be written as

$$
\eta_{s} e^{-C t} \frac{d^{\beta} \varepsilon^{v p}(t)}{d t^{\beta}}+\sigma_{s}=\sigma
$$

By manipulation, (22) can also be rewritten as

$$
\frac{d^{\beta} \varepsilon^{v p}(t)}{d t^{\beta}}=\frac{\sigma-\sigma_{s}}{\eta_{s}} e^{C t} .
$$

Based on the Riemann-Liouville definition, applying $\alpha$ order integral to (23), we have

$$
\varepsilon^{v p}(t)=\frac{\sigma-\sigma_{s}}{\eta_{s} \Gamma(\beta)} \int_{0}^{t}(t-\tau)^{\beta-1} e^{C t} d \tau .
$$

By the Taylor expansion of $e^{C t}=\sum_{k=0}^{\infty}\left((C x)^{k} / k !\right)$ in the same way, we can get

$$
\varepsilon^{v p}(t)=\frac{\sigma-\sigma_{s}}{\eta_{s}} t^{\beta} \sum_{k=0}^{\infty} \frac{(C t)^{k}}{\Gamma(\beta+1+k)} .
$$

From the deduction in Sections (i) and (ii), we obtain the total stain as follows:

$$
\varepsilon^{v p}(t)= \begin{cases}\frac{\sigma-\sigma_{s}}{\eta_{s}} \frac{t^{\beta}}{\Gamma(1+\beta)} & \sigma<\sigma_{\infty} \\ \frac{\sigma-\sigma_{s}}{\eta_{s}} t^{\beta} \sum_{k=0}^{\infty} \frac{(C t)^{k}}{\Gamma(\beta+1+k)} & \sigma \geq \sigma_{\infty} .\end{cases}
$$

So, in summary, the constitutive equation of the model in one dimension is expressed as

$$
\varepsilon=\varepsilon^{e}+\varepsilon^{v e}(t)+\varepsilon^{v p}(t)=\left\{\begin{array}{lc}
\frac{\sigma}{E}+\frac{\sigma}{\eta_{\alpha}} t^{\alpha}\left[\frac{1}{\Gamma(\alpha+1)}+A \sum_{n=1}^{\infty} \frac{(-B t)^{n}}{\Gamma(\alpha+1+n)}\right] & \sigma<\sigma_{s} \\
\frac{\sigma}{E}+\frac{\sigma}{\eta_{\alpha}} t^{\alpha}\left[\frac{1}{\Gamma(\alpha+1)}+A \sum_{n=1}^{\infty} \frac{(-B t)^{n}}{\Gamma(\alpha+1+n)}\right]+\frac{\sigma-\sigma_{s}}{\eta_{s} \Gamma(\beta+1)} t & \sigma_{s} \leq \sigma<\sigma_{\infty} \\
\frac{\sigma}{E}+\frac{\sigma}{\eta_{\alpha}} t^{\alpha}\left[\frac{1}{\Gamma(\alpha+1)}+A \sum_{n=1}^{\infty} \frac{(-B t)^{n}}{\Gamma(\alpha+1+n)}\right]+\frac{\sigma-\sigma_{s}}{\eta_{s}} t^{\beta} \sum_{k=0}^{\infty} \frac{(C t)^{k}}{\Gamma(\beta+1+k)} & \sigma \geq \sigma_{\infty} .
\end{array}\right.
$$

3.4. Three-Dimensional Formulation of the Creep Constitutive Model. In general, the soil is in the three-dimensional stress state, and the shear deformation is the main source of creep. Thus, in this study, the volume deformation is not considered.

In three-dimensional stress state, the total strain of the model can be expressed as

$$
\varepsilon_{i j}=\varepsilon_{i j}{ }^{e}+\varepsilon_{i j}{ }^{v e}+\varepsilon_{i j}{ }^{v p}
$$

According to the generalized Hook's law, the threedimensional constitutive equation for elastic element is

$$
\begin{aligned}
e_{i j} & =\frac{1}{2 G_{0}} s_{i j}, \\
\varepsilon_{k k} & =\frac{1}{3 K} \sigma_{k k},
\end{aligned}
$$

where $s_{i j}$ and $e_{i j}$ are the stress deviator tensor and strain deviator tensor, respectively; $\sigma_{k k}$ and $\varepsilon_{k k}$ are the first invariant of the stress tensor and the first invariant of the strain tensor, respectively. $G_{0}$ and $K$ are the initial shear modulus and the initial bulk modulus, respectively.

Therefore, without considering the volume change, the strain of elastic element can be expressed as

$$
\varepsilon_{i j}^{e}=\frac{1}{2 G_{0}} s_{i j}
$$

And the strain of the viscoelasticity element can be expressed as

$$
\varepsilon_{i j}{ }^{\nu e}(t)=\frac{s_{i j}}{2 H_{\alpha}} t^{\alpha}\left[\frac{1}{\Gamma(\alpha+1)}+A \sum_{n=1}^{\infty} \frac{(-B t)^{n}}{\Gamma(\alpha+1+n)}\right] \text {, }
$$

where $H_{\alpha}$ is the viscosity coefficient of the viscoelasticity element. 
In the same way, the strain of viscoplastic element can be expressed as

$$
\begin{aligned}
\varepsilon_{i j}{ }^{p p}(t) & \begin{cases}\frac{1}{2 H_{s}} \frac{t^{\beta}}{\Gamma(1+\beta)}\left\langle\phi\left(\frac{F}{F_{0}}\right)\right\rangle \frac{\partial Q}{\partial \sigma_{i j}} & \sigma_{s} \leq q<\sigma_{\infty} \\
\frac{1}{2 H_{s}} t^{\beta} \sum_{k=0}^{\infty} \frac{(C t)^{k}}{\Gamma(\beta+1+k)}\left\langle\phi\left(\frac{F}{F_{0}}\right)\right\rangle \frac{\partial Q}{\partial \sigma_{i j}} & q \geq \sigma_{\infty},\end{cases}
\end{aligned}
$$

where $H_{s}$ is the viscosity coefficient of the viscoplasticity element; $F$ is the yield function; $F_{0}$ is the initial reference of the yield surface and can be taken as 1.0; $Q$ is the plastic potential function, and the tested material is assumed to be associated flow rule which is $F=Q$; and $\phi(\cdot)$ is the form of the power function, and its exponent sign is taken as 1.0. So (32) can be rewritten as

$$
\begin{aligned}
\varepsilon_{i j}{ }^{\nu p}(t) & \begin{cases}\frac{1}{2 H_{s}} \frac{t^{\beta}}{\Gamma(1+\beta)} \frac{F}{F_{0}} \frac{\partial F}{\partial \sigma_{i j}} & q<\sigma_{\infty} \\
\frac{1}{2 H_{s}} t^{\beta} \sum_{k=0}^{\infty} \frac{(C t)^{k}}{\Gamma(\beta+1+k)} \frac{F}{F_{0}} \frac{\partial F}{\partial \sigma_{i j}} & q \geq \sigma_{\infty} .\end{cases}
\end{aligned}
$$

Substituting (30), (31), and (33) into (28), we can get

$$
\begin{aligned}
\varepsilon_{i j}(t)= & \varepsilon_{i j}{ }^{e}+\varepsilon_{i j}{ }^{v e}(t)+\varepsilon_{i j}{ }^{v p}(t) \\
& =\left\{\begin{array}{lc}
\frac{1}{2 G_{0}} s_{i j}+\frac{s_{i j}}{2 H_{\alpha}} t^{\alpha}\left[\frac{1}{\Gamma(\alpha+1)}+A \sum_{n=1}^{\infty} \frac{(-B t)^{n}}{\Gamma(\alpha+1+n)}\right] & F<0 \\
\frac{1}{2 G_{0}} s_{i j}+\frac{s_{i j}}{2 H_{\alpha}} t^{\alpha}\left[\frac{1}{\Gamma(\alpha+1)}+A \sum_{n=1}^{\infty} \frac{(-B t)^{n}}{\Gamma(\alpha+1+n)}\right]+\frac{1}{2 H_{s}} \frac{t^{\beta}}{\Gamma(1+\beta)} \frac{F}{F_{0}} \frac{\partial F}{\partial \sigma_{i j}} & F=0, q<\sigma_{\infty} \\
\frac{1}{2 G_{0}} s_{i j}+\frac{s_{i j}}{2 H_{\alpha}} t^{\alpha}\left[\frac{1}{\Gamma(\alpha+1)}+A \sum_{n=1}^{\infty} \frac{(-B t)^{n}}{\Gamma(\alpha+1+n)}\right]+\frac{1}{2 H_{s}} t^{\beta} \sum_{k=0}^{\infty} \frac{(C t)^{k}}{\Gamma(\beta+1+k)} \frac{F}{F_{0}} \frac{\partial F}{\partial \sigma_{i j}} \quad F=0, q \geq \sigma_{\infty} .
\end{array}\right.
\end{aligned}
$$

As mentioned above, the impact of the spherical stress tensor on creep of frozen soils can be neglected. So the yield function can be chosen as

$$
F=\sqrt{J_{2}}-\frac{\sigma_{s}}{\sqrt{3}}
$$

$$
\begin{aligned}
s_{1} & =\sigma_{1}-\sigma_{m}=\frac{2}{3}\left(\sigma_{1}-\sigma_{3}\right), \\
\sqrt{J_{2}} & =\frac{1}{\sqrt{3}}\left(\sigma_{1}-\sigma_{3}\right) .
\end{aligned}
$$

Under the triaxial creep test, $\sigma_{2}=\sigma_{3}$, and thus we have

$$
\sigma_{m}=\frac{1}{3}\left(\sigma_{1}+2 \sigma_{3}\right)
$$

Thus, (34) can be rewritten as

$$
\varepsilon_{1}(t)= \begin{cases}\frac{\sigma_{1}-\sigma_{3}}{3 G_{0}}+\frac{\sigma_{1}-\sigma_{3}}{3 H_{\alpha}} t^{\alpha}\left[\frac{1}{\Gamma(\alpha+1)}+A \sum_{n=1}^{\infty} \frac{(-B t)^{n}}{\Gamma(\alpha+1+n)}\right] & F<0 \\ \frac{\sigma_{1}-\sigma_{3}}{3 G_{0}}+\frac{\sigma_{1}-\sigma_{3}}{3 H_{\alpha}} t^{\alpha}\left[\frac{1}{\Gamma(\alpha+1)}+A \sum_{n=1}^{\infty} \frac{(-B t)^{n}}{\Gamma(\alpha+1+n)}\right]+\frac{\sigma_{1}-\sigma_{3}-\sigma_{s}}{6 H_{s}} \frac{t^{\beta}}{\Gamma(1+\beta)} & F=0, q<\sigma_{\infty} \\ \frac{\sigma_{1}-\sigma_{3}}{3 G_{0}}+\frac{\sigma_{1}-\sigma_{3}}{3 H_{\alpha}} t^{\alpha}\left[\frac{1}{\Gamma(\alpha+1)}+A \sum_{n=1}^{\infty} \frac{(-B t)^{n}}{\Gamma(\alpha+1+n)}\right]+\frac{\sigma_{1}-\sigma_{3}-\sigma_{s}}{6 H_{s}} t^{\beta} \sum_{k=0}^{\infty} \frac{(C t)^{k}}{\Gamma(\beta+1+k)} \quad F=0, q \geq \sigma_{\infty} .\end{cases}
$$

\section{The Determination of Model Parameters and Model Verification}

\subsection{The Determination of Parameters}

4.1.1. The Initial Shear Modulus $G_{0}$. By the triaxial creep tests, we can obtain the different initial stain under different shear stress level as shown in Figure 6. So we can get the initial shear modulus under the confining pressures of $0.3 \mathrm{MPa}, 1.4 \mathrm{MPa}$, and 6.0 MPa which are 1.859 $\mathrm{MPa}, 1.275 \mathrm{MPa}$, and 1.206 $\mathrm{MPa}$, respectively.
4.1.2. Yield Stress $\sigma_{s}$ and Long-Term Strength $\sigma_{\infty}$. Yield stress $\sigma_{s}$ can be obtained by the stress-stain curve of triaxial tests as shown in Figure 7 [25], where we take the result of confining pressure of $0.3 \mathrm{MPa}$ as an example. So the yield stresses under the confining pressures of $0.3 \mathrm{MPa}, 1.4 \mathrm{MPa}$, and 6.0 $\mathrm{MPa}$ are 4.21 $\mathrm{MPa}$, 4.38 $\mathrm{MPa}$, and 4.42 $\mathrm{MPa}$, respectively.

Long-term strength $\sigma_{\infty}$ is a threshold shear stress between the attenuate creep and nonattenuate creep. The test specimen will finally behave an accelerating failure stage once it enters the steady creep stage with a constant creep rate, and 


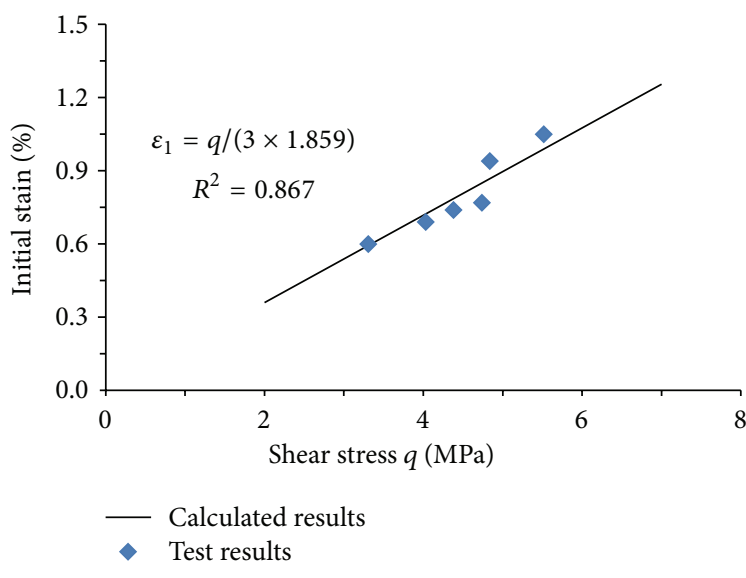

(a) $\sigma_{3}=0.3 \mathrm{MPa}$

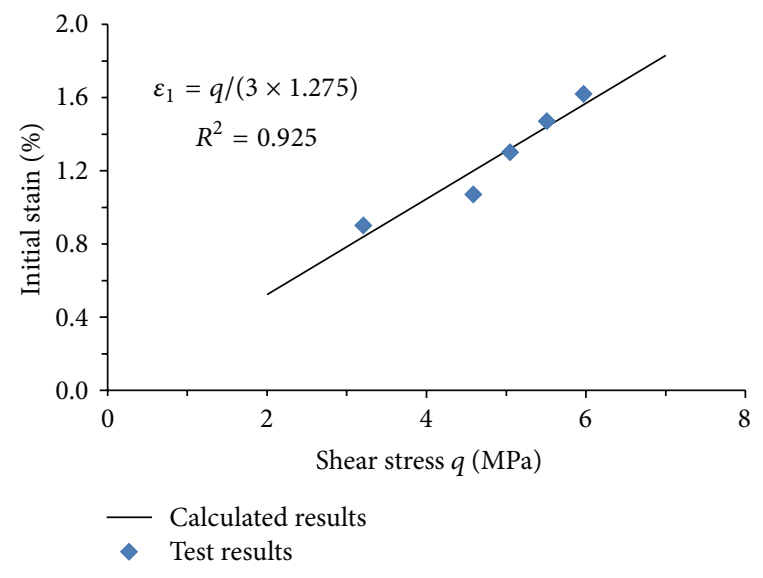

(b) $\sigma_{3}=1.4 \mathrm{MPa}$

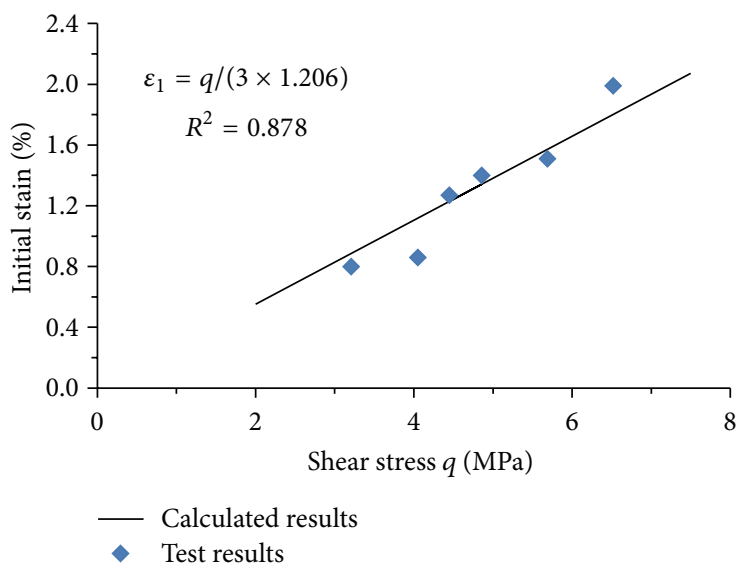

(c) $\sigma_{3}=6.0 \mathrm{MPa}$

FiguRE 6: The initial elastic shear modulus under different confining pressures.

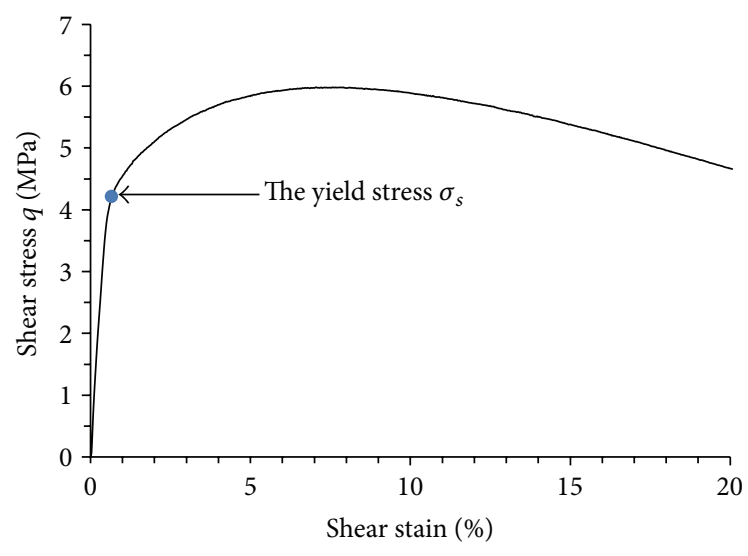

FIGURE 7: The yield stress under confining pressure of $0.3 \mathrm{MPa}$.

in this stage, the greater the shear stress is, the larger the creep rate is. So based on the creep rate of the steady creep stage, a method is put forward to determine the long-term creep strength. Firstly, the relationship between the creep rate of steady creep stage and the shear stress is obtained as shown in Figure 8 . Then an equation is proposed to fit the relationship between the rate and the shear stress as follows:

$$
q=\sigma_{\infty}+k \ln \left(1+\frac{v}{v_{0}}\right)
$$

where $q$ is the shear stress; $k$ is a material constant, whose unit is MPa; $v$ is the creep rate of steady creep stage; $v_{0}$ is the reference of creep rate and can be taken as $1 \% \cdot \mathrm{h}^{-1}$.

So according to (38), we can obtain the long-term strength of test specimen under the confining pressure of $0.3 \mathrm{MPa}$ which is $4.228 \mathrm{MPa}$. From Figures 3(b) and 3(c), under the confining pressures of 1.4 MPa and 6.0 MPa, there is no steady creep stage. That is, the strengthening effect is predominant in this stage. So we think narrowly that the longterm strength is greater than the maximum load.

4.1.3. Hardening Parameters $A$ and B. Under the same confining pressure, the greater the shear stress is, the faster and the stronger the strengthening effect is. So the relationship between $A$ and the shear stress and the relationship between 


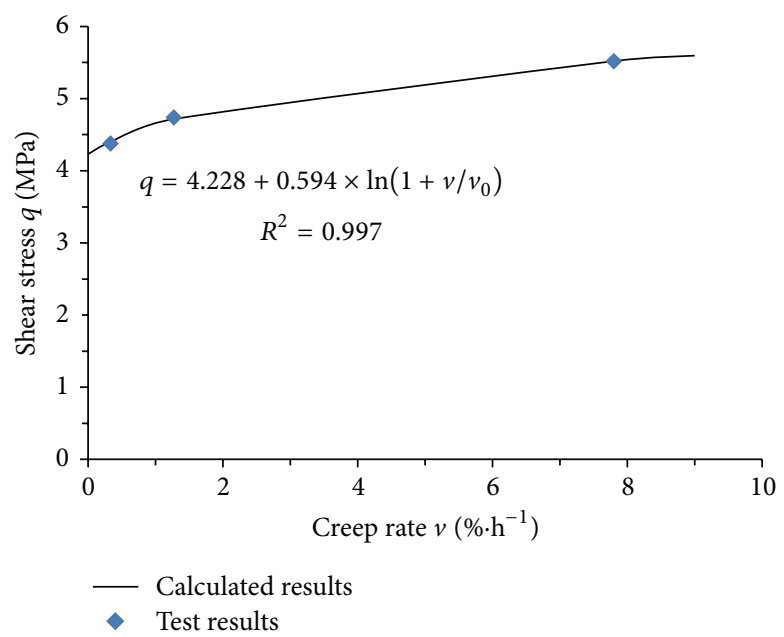

FIGURE 8: The long-term strength under the confining pressure of 0.3 MPa.

$B$ and the shear stress are assumed to be exponential form as follows:

$$
\begin{aligned}
& A=e^{-\lambda q}, \\
& B=e^{\theta q}-1,
\end{aligned}
$$

where $\lambda$ and $\theta$ are the parameters, $\lambda>0$ and $\theta>0$, whose units are $\mathrm{MPa}^{-1}$, and can be obtained by fitting the test results when $F<0$.

4.1.4. Parameters of Viscoelastic Elements $\alpha$ and $H_{\alpha}$. Under the same confining pressure, $\alpha$ is constant. The shear modulus of viscoelastic element $H_{\alpha}$ decreases with the increasing shear stress in the form of exponent, and thus, it is assumed as follows:

$$
H_{\alpha}=a e^{-b q}
$$

where $a$ and $b$ are the parameters, whose units are MPa $h^{\alpha}$ and $\mathrm{MPa}^{-1}$, respectively.

4.1.5. Parameters of Viscoplastic Elements $\beta$ and $H_{s}$. Under the same confining pressure, the fractional order parameter $\beta$ increases with the increase of the shear stress, and the shear modulus of the viscoplastic element decreases with the increase of shear stress, indicating that the creep rate increases with the increase of the shear stress. Therefore, it is assumed that

$$
\begin{aligned}
\beta & =\kappa \exp \left[\mu\left(\frac{q-\sigma_{s}}{\sigma_{s}}\right)\right], \\
H_{s} & =c \ln \left[\frac{\left(q-\sigma_{s}\right)}{\sigma_{s}}\right]+d,
\end{aligned}
$$

where $\kappa, \mu, c$, and $d$ are the parameters. $\kappa$ and $\mu$ are dimensionless, and the units of $c$ and $d$ are $\mathrm{MPa} \cdot \mathrm{h}^{\beta}$.
4.2. Model Verification. From the triaxial creep test results under the three confining pressures, the proposed model parameters are given in Table 2, and the calculated results of creep curves are shown in Figure 9. From Figure 9, it is found that the calculated results of the proposed model are in good agreement with the tested results under the different confining pressures (e.g., 0.3 $\mathrm{MPa}, 1.4 \mathrm{MPa}$, and 6.0 MPa). The proposed model can not only accurately reproduce the unsteady stage when the shear stress is lower than the longterm strength but also predict the steady stage and progressive stage when the shear stress is greater than the long-term strength.

\section{Conclusions}

Based on the analysis of a series of the triaxial creep tests results of frozen silty clay mixed with sands, a fractional order creep constitutive model in consideration of the strengthening and weakening effects simultaneously is formulated to predict the creep deformation behavior of frozen soil. Some conclusions can be drawn as follows:

(1) The test results show that the specimen exhibits an attenuate creep when the shear stress is lower than the long-term strength, and it exhibits an accelerating creep failing in accelerating stage when the shear stress is greater than the long-term strength. The long-term strength is associated with the confining pressure, and the strengthening and weakening effects are confirmed in the test.

(2) The hardening parameter and the damage variable are introduced here to describe the strengthening and weakening effects in the process of creep. By considering the creep mechanism, a fractional creep constitutive model is put forward, and the three-dimensional formulation of the model is also deduced.

(3) Though validating the proposed model by the test data of frozen silty clay mixed with sands under 


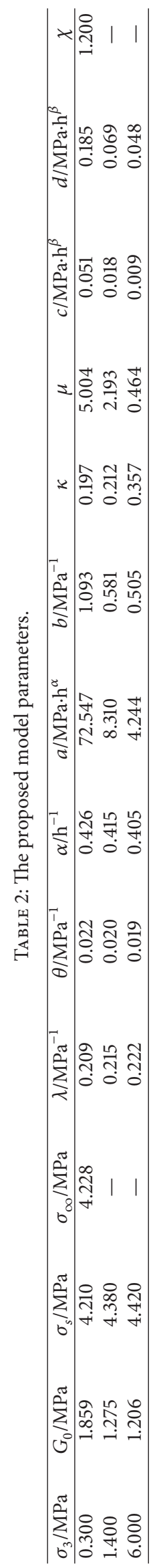




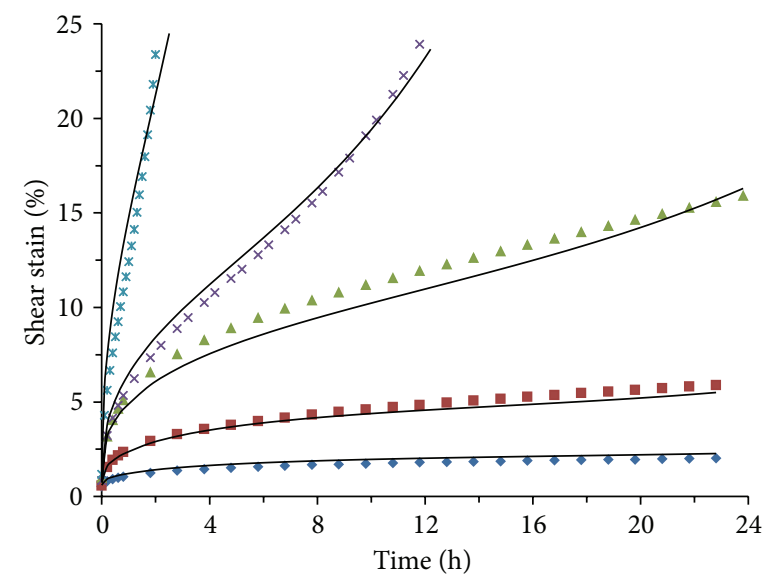

- Tested results $q=3.31 \mathrm{MPa} \quad \times \quad$ Tested results $q=4.74 \mathrm{MPa}$

- Tested results $q=4.03 \mathrm{MPa} \quad * \quad$ Tested results $q=5.52 \mathrm{MPa}$

$\Delta$ Tested results $q=4.38 \mathrm{MPa} \longrightarrow$ Calculated results

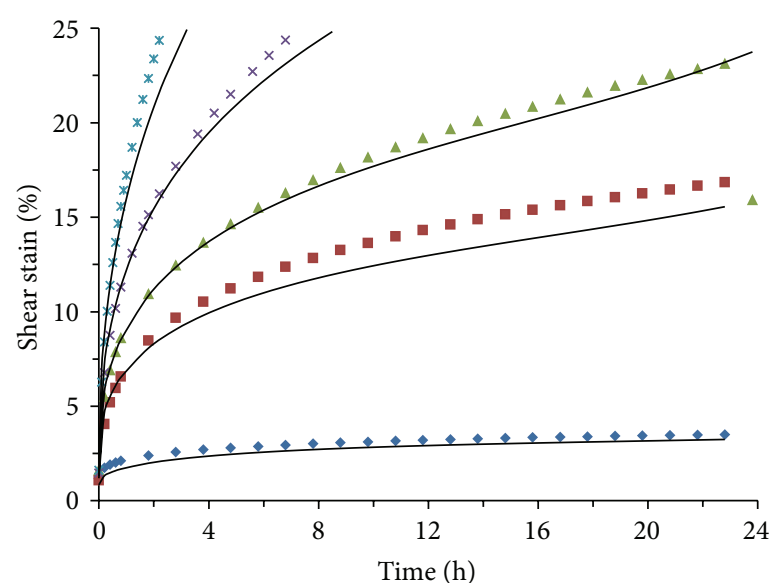

- Tested results $q=3.21 \mathrm{MPa} \quad \times \quad$ Tested results $q=5.51 \mathrm{MPa}$

- Tested results $q=4.59 \mathrm{MPa} \quad * \quad$ Tested results $q=5.97 \mathrm{MPa}$

$\Delta$ Tested results $q=5.05 \mathrm{MPa}$ Calculated results

(a) $\sigma_{3}=0.3 \mathrm{MPa}$

(b) $\sigma_{3}=1.4 \mathrm{MPa}$
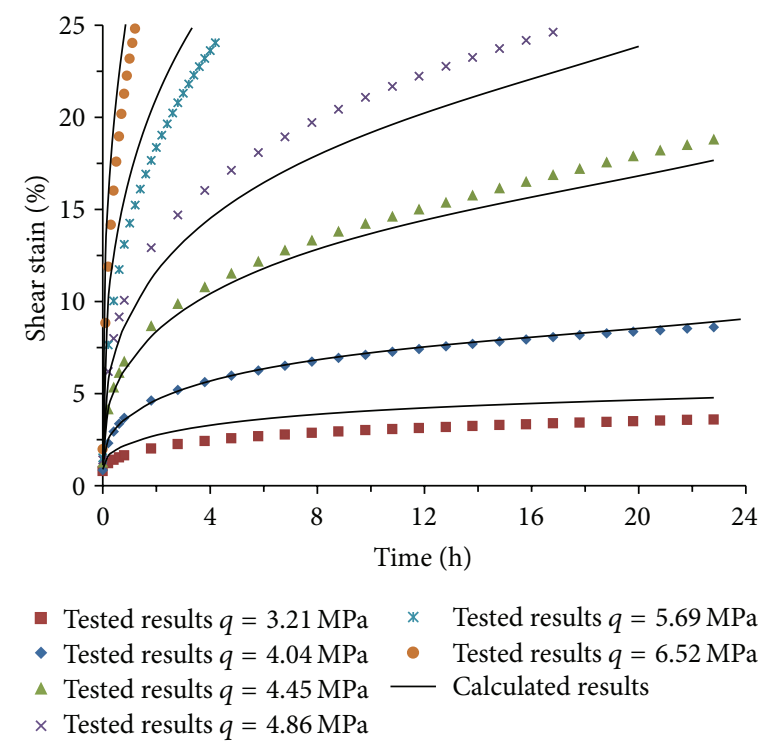

(c) $\sigma_{3}=6.0 \mathrm{MPa}$

FIgURE 9: Comparison between tested results and calculated results.

different confining pressures, it is found that the proposed model can describe the creep behavior of frozen silty clay mixed with sands well.

\section{Competing Interests}

The authors declare that there are no competing interests regarding the publication of this paper.

\section{Acknowledgments}

The authors appreciate the funding of the CAS Pioneer Hundred Talents Program, the National Natural Science Foundation of China (Grant no. 71373245).

\section{References}

[1] Y. M. Lai, X. T. Xu, Y. H. Dong, and S. Y. Li, "Present situation and prospect of mechanical research on frozen soils in China," Cold Regions Science and Technology, vol. 87, pp. 6-18, 2013.

[2] G. D. Cheng, Z. H. Sun, and F. J. Niu, "Application of the roadbed cooling approach in Qinghai-Tibet railway engineering," Cold Regions Science and Technology, vol. 53, no. 3, pp. 241-258, 2008.

[3] X. L. Yao, J. L. Qi, and W. Wu, "Three dimensional analysis of large strain thaw consolidation in permafrost," Acta Geotechnica, vol. 7, no. 3, pp. 193-202, 2012.

[4] L. Wang, W. Wang, and F. Yu, "Thaw consolidation behaviours of embankments in permafrost regions with periodical temperature boundaries," Cold Regions Science and Technology, vol. 109, pp. 70-77, 2015. 
[5] M. Roustaei, A. Eslami, and M. Ghazavi, "Effects of freezethaw cycles on a fiber reinforced fine grained soil in relation to geotechnical parameters," Cold Regions Science and Technology, vol. 120, pp. 127-137, 2015.

[6] F. Yu, J. L. Qi, X. L. Yao, and Y. Z. Liu, "In-situ monitoring of settlement at different layers under embankments in permafrost regions on the Qinghai-Tibet Plateau," Engineering Geology, vol. 160, pp. 44-53, 2013.

[7] Y. G. Yang, Y. M. Lai, and X. X. Chang, "Experimental and theoretical studies on the creep behavior of warm ice-rich frozen sand," Cold Regions Science and Technology, vol. 63, no. 1-2, pp. 61-67, 2010.

[8] D.-W. Li, J.-H. Fan, and R.-H. Wang, "Research on viscoelastic-plastic creep model of artificially frozen soil under high confining pressures," Cold Regions Science and Technology, vol. 65, no. 2, pp. 219-225, 2011.

[9] S. H. Wang, J. L. Qi, Z. Y. Yin, J. M. Zhang, and W. Ma, "A simple rheological element based creep model for frozen soils," Cold Regions Science and Technology, vol. 106-107, pp. 47-54, 2014.

[10] M. Enelund, L. Mähler, K. Runesson, and B. L. Josefson, "Formulation and integration of the standard linear viscoelastic solid with fractional order rate laws," International Journal of Solids and Structures, vol. 36, no. 16, pp. 2417-2442, 1999.

[11] H. W. Zhou, C. P. Wang, B. B. Han, and Z. Q. Duan, "A creep constitutive model for salt rock based on fractional derivatives," International Journal of Rock Mechanics and Mining Sciences, vol. 48, no. 1, pp. 116-121, 2011.

[12] H. W. Zhou, C. P. Wang, L. Mishnaevsky Jr., Z. Q. Duan, and J. Y. Ding, "A fractional derivative approach to full creep regions in salt rock," Mechanics of Time-Dependent Materials, vol. 17, no. 3, pp. 413-425, 2013.

[13] J. H. Kang, F. B. Zhou, C. Liu, and Y. K. Liu, "A fractional non-linear creep model for coal considering damage effect and experimental validation," International Journal of Non-Linear Mechanics, vol. 76, pp. 20-28, 2015.

[14] C. A. Baldwin, A. J. Sederman, M. D. Mantle, P. Alexander, and L. F. Gladden, "Determination and characterization of the structure of a pore space from 3D volume images," Journal of Colloid and Interface Science, vol. 181, no. 1, pp. 79-92, 1996.

[15] R. I. Al-Raoush and C. S. Willson, "Extraction of physically realistic pore network properties from three-dimensional synchrotron X-ray microtomography images of unconsolidated porous media systems," Journal of Hydrology, vol. 300, no. 1-4, pp. 44-64, 2005.

[16] J. K. Torrance, T. Elliot, R. Martin, and R. J. Heck, "X-ray computed tomography of frozen soil," Cold Regions Science and Technology, vol. 53, no. 1, pp. 75-82, 2008.

[17] T. D. Miao, X. X. Wei, and C. Q. Zhang, "Creep of frozen soil by damage mechanics," Science in China(Series B), vol. 38, no. 8, pp. 996-1002, 1995.

[18] Y.-P. Yao, W. Hou, and A.-N. Zhou, "UH model: three-dimensional unified hardening model for overconsolidated clays," Geotechnique, vol. 59, no. 5, pp. 451-469, 2009.

[19] Y.-P. Yao, L.-M. Kong, A.-N. Zhou, and J.-H. Yin, "Timedependent unified hardening model: three-dimensional elastoviscoplastic constitutive model for clays," Journal of Engineering Mechanics, vol. 141, no. 6, Article ID 04014162, 2015.

[20] Y. P. Yao and A. N. Zhou, "Non-isothermal unified hardening model: a thermo-elastoplastic model for clays," Geotechnique, vol. 63, no. 15, pp. 1328-1345, 2013.
[21] Q. Y. Fan, K. Q. Yang, and W. M. Wang, "Study of creep mechanism of argillaceous soft rocks," Chinese Journal of Rock Mechanics and Engineering, vol. 29, no. 8, pp. 1555-1561, 2010 (Chinese).

[22] Y. M. Lai, J. B. Li, and Q. Z. Li, "Study on damage statistical constitutive model and stochastic simulation for warm ice-rich frozen silt," Cold Regions Science and Technology, vol. 71, pp. 102-110, 2012.

[23] X. Li, W.-G. Cao, and Y.-H. Su, "A statistical damage constitutive model for softening behavior of rocks," Engineering Geology, vol. 143-144, pp. 1-17, 2012.

[24] W. Yang, Q. Zhang, S. Li, and S. Wang, "Time-dependent behavior of diabase and a nonlinear creep model," Rock Mechanics and Rock Engineering, vol. 47, no. 4, pp. 1211-1224, 2014.

[25] W. Ma and D. Y. Wang, Mechanics of Frozen Ground, Science Press, Beijing, China, 2014 (Chinese). 

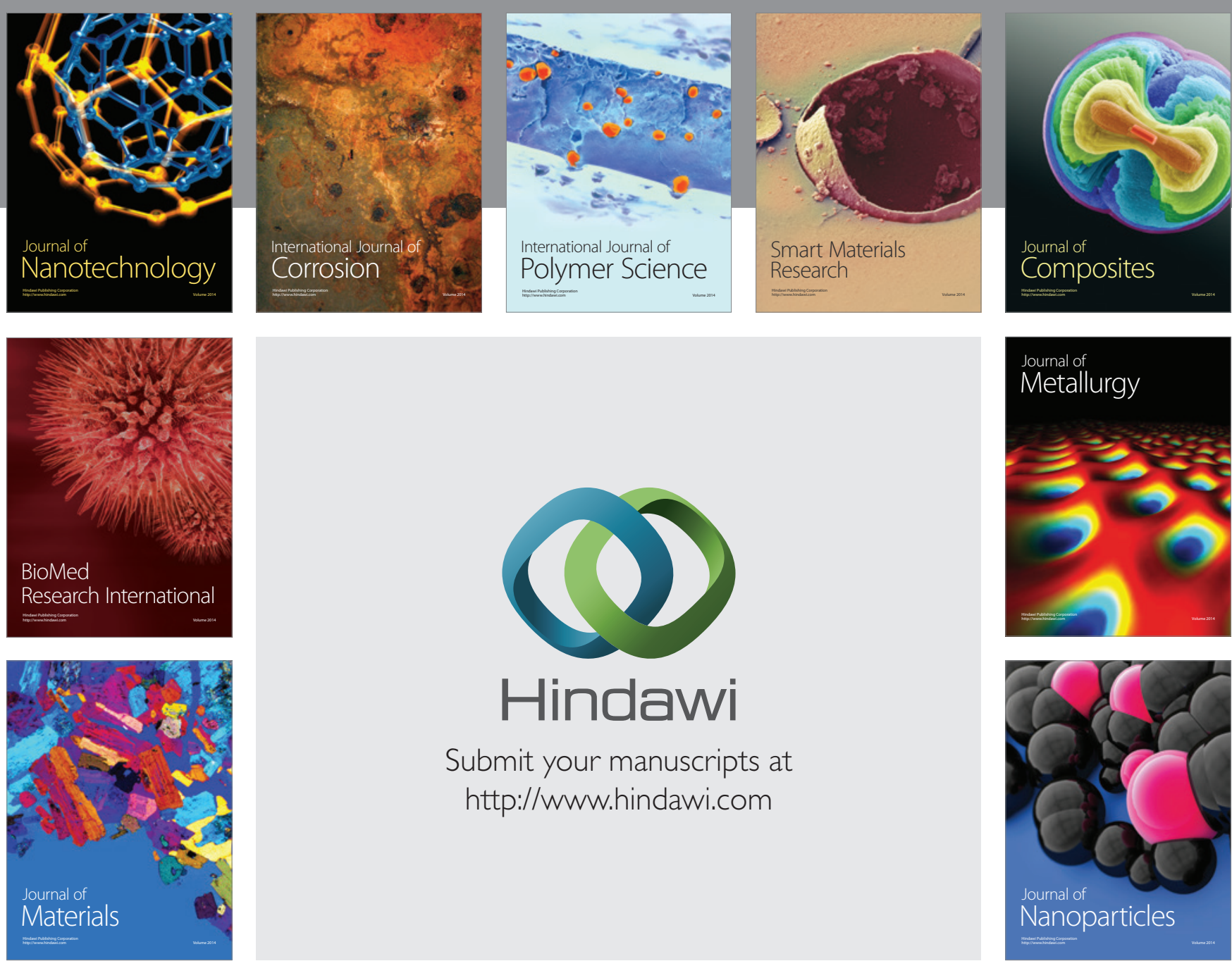

\section{Hindawi}

Submit your manuscripts at

http://www.hindawi.com

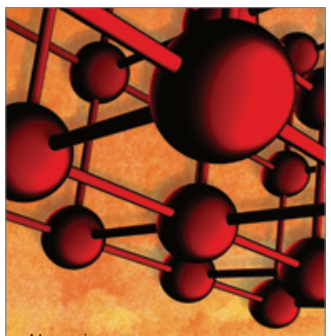

Materials Science and Engineering
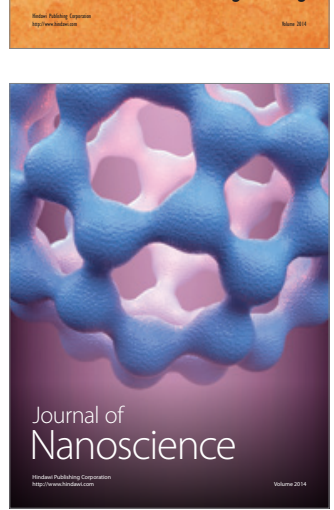
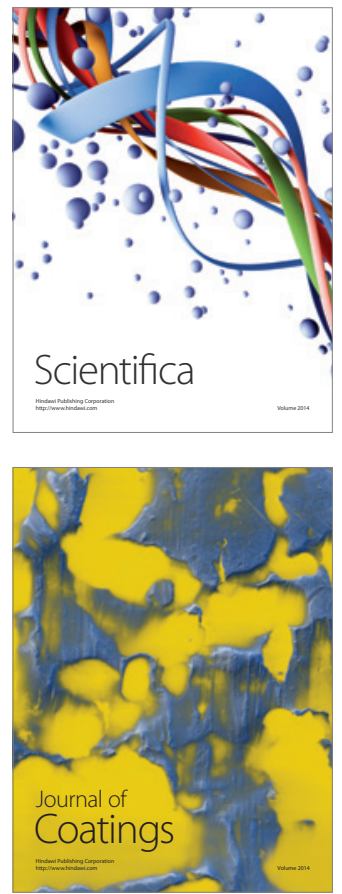
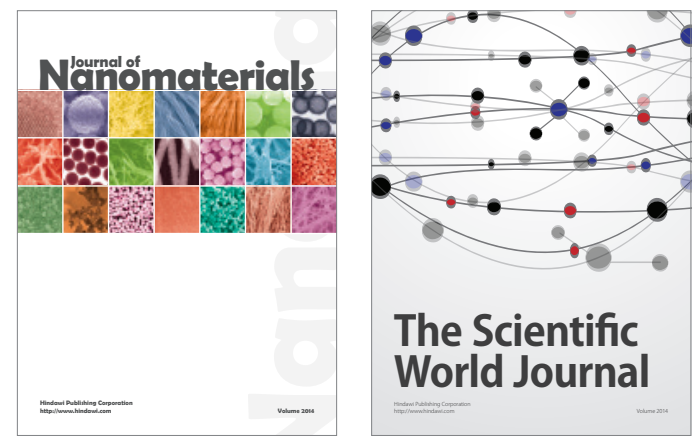

The Scientific World Journal
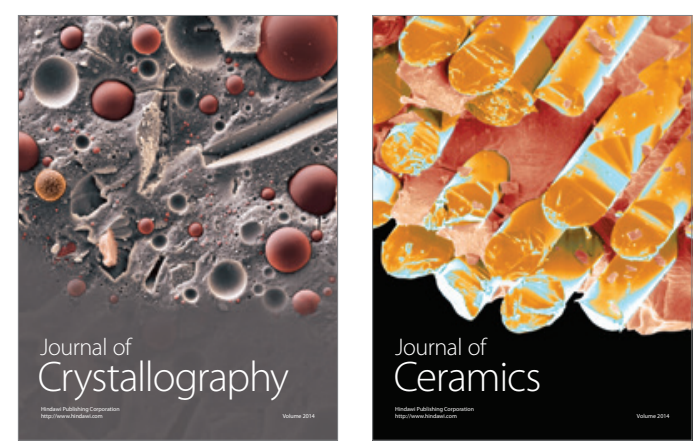
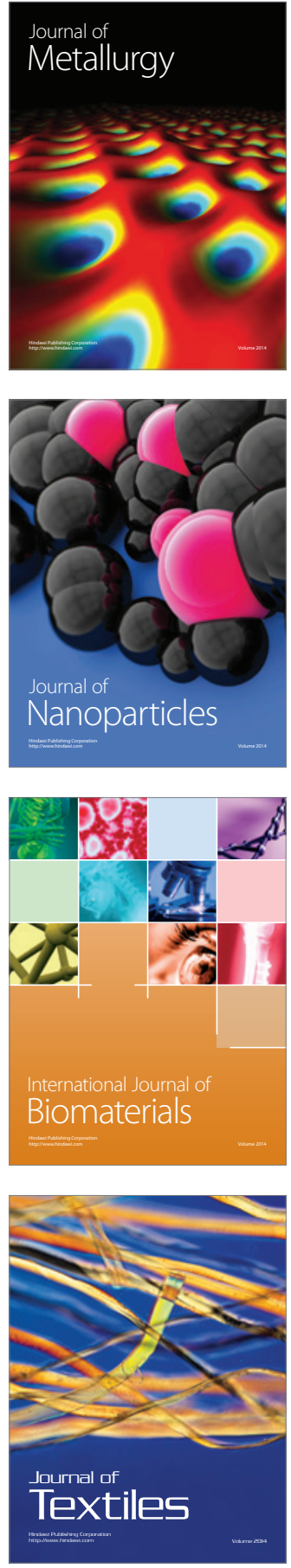